
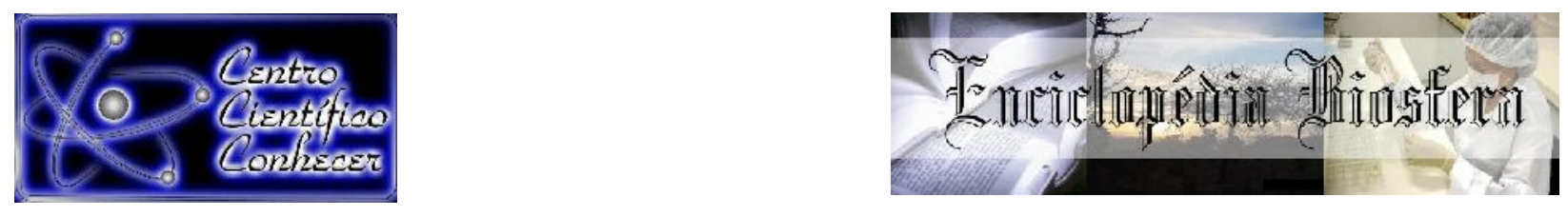

\title{
EXTRATOS HERBAIS COMO MELHORADOR DE DESEMPENHO NA DIETA EM TILÁPIAS
}

\author{
Alan Fernando Baretta ${ }^{1}$; Gabriel Rossato ${ }^{1}$, Edemar Aniecevski ${ }^{2}$, Paulo Cesar \\ Guarnieri $^{3}$, Tiago Goulart Petrolli ${ }^{3}$ \\ ${ }^{1}$ Universidade do Oeste de Santa Catarina, Graduação em Zootecnia, Xanxerê-SC, \\ Brasil. Bolsista UNIEDU/SC. \\ ${ }^{2}$ Universidade do Oeste de Santa Catarina, Graduação em Zootecnia, Xanxerê-SC, \\ Brasil. Bolsista PIBIC/CNPq. \\ ${ }^{3}$ Universidade do Oeste de Santa Catarina, Programa de Mestrado em Sanidade e \\ Produção Animal, Xanxerê-SC, Brasil. \\ E-mail: tiago.petrolli@unoesc.edu.br
}

Recebido em: 06/04/2019 - Aprovado em: 10/06/2019 - Publicado em: 30/06/2019
DOl: 10.18677/EnciBio_2019A68

\begin{abstract}
RESUMO
Com o intuito de mitigar o uso excessivo de antibióticos promotores de crescimento na produção animal, torna-se necessário buscar alternativas viáveis, a fim de evitar a resistência cruzada uma vez que esses animais são destinados ao consumo humano. Com isso, objetivou-se nesse trabalho avaliar o efeito dos extratos herbais como promotores de crescimento diante das características zootécnicas de desempenho e de contagem microbiana intestinal em peixes. Foram utilizadas 120 tilápias da linhagem GIFT, com aproximadamente três centímetros de comprimento, distribuídas em delineamento inteiramente casualizado, composto por três tratamentos $(0,50 \mathrm{Mg} / \mathrm{kg}$ e $100 \mathrm{Mg} / \mathrm{kg}$ de extratos herbais) e quatro repetições, com 10 animais em cada repetição, por um período experimental de 42 dias. $\mathrm{O} \mathrm{pH}$ e as concentrações de oxigênio dissolvido na água estiveram dentro dos valores aceitáveis para o cultivo, entretanto a temperatura ficou abaixo do ideal em decorrência do experimento ter sido conduzido no período de transição entre inverno e primavera. $\mathrm{O}$ ganho de peso entre os peixes dos diferentes tratamentos não diferiu $(P>0,05)$. Em relação à contagem microbiana intestinal, as tilápias alimentadas com dietas contendo extratos herbais apresentaram menores valores de unidades formadoras de colônias/ml $(\mathrm{p}<0,05)$ quando comparadas aos peixes alimentados com a dieta controle. Com isso é possível concluir que, nas dosagens testadas, os extratos herbais não foram suficientes para alterar significativamente o desempenho zootécnico dos alevinos, todavia, foram capazes de influenciar positivamente na flora intestinal desses animais.
\end{abstract}

PALAVRAS-CHAVE: Antibióticos, nutrição, piscicultura. 


\title{
HERBAL EXTRACTS AS A PERFORMANCE IMPROVEMENT IN TILAPIA DIETS
}

\begin{abstract}
In order to mitigate the excessive use of antibiotic growth promoters in animal production, it is necessary to seek viable alternatives in order to avoid crossresistance once these animals are intended for human consumption. Thus, the objective of this work was to evaluate the effect of the herbal extracts as growth promoters in relation to performance zootechnical characteristics and intestinal microbial counts in fish. A total of 120 tilapia of the GIFT lineage, approximately three centimeters long, were distributed in a completely randomized design, consisting of three treatments $(0.50 \mathrm{mg} / \mathrm{kg}$ and $100 \mathrm{mg} / \mathrm{kg}$ of herbal extracts) and four replicates, with 10 animals in each replicate, for an experimental period of 42 days. The $\mathrm{pH}$ and dissolved oxygen concentrations in the water were within acceptable values for the crop, however, the temperature was below ideal because the experiment was conducted in the transition period between winter and spring. The weight gain among the fish of the different treatments did not differ ( $p>0.05)$. In relation to the intestinal microbial count, tilapia fed diets containing herbal extracts had lower values of colony forming units $/ \mathrm{ml}(\mathrm{p}<0.05)$ when compared to fish fed with the control diet. With this, it is possible to conclude that, in the tested doses, the herbal extracts were not enough to significantly alter the zootechnical performance of the fingerlings, however, they were able to positively influence the intestinal flora of these animals.
\end{abstract}

KEYWORDS: Antibiotics, fisheries, nutrition.

\section{INTRODUÇÂO}

Segundo o SEBRAE (2015), a piscicultura envolve a criação de peixes comercialmente em tanques, lagoas, lagos, rios e oceano, geralmente destinados à alimentação. Como ressaltam $\mathrm{Hu}$ et al. (2015), a expansão da aquicultura sustentável depende do desenvolvimento e aplicações de novas tecnologias que intensifiquem os cultivos, maximizem a utilização de água e nutrientes, além de minimizar os impactos ambientais. E é nesse sentido que a utilização de recursos que diminuem o risco a saúde humana entram em pauta.

Segundo Barroso et al. (2017), a produção de tilápias, cultivo mais comumente encontrado no Brasil, é voltada quase que em sua totalidade ao mercado interno, sendo que apenas $1 \%$ da produção é destinada à exportação.

Apesar de ser muito lucrativa, a piscicultura vem sendo muito explorada em nossa região como uma atividade secundária devido a vários desafios inerentes a produção e poucos profissionais com qualificação nessa área. Todavia, algumas propriedades passam a explora-la como a atividade principal, e assim, sofrendo com uma alta densidade de peixes causando um aumento no estresse do animal (TELLI et al., 2014; KALAMA et al., 2017), problemas de doenças e limitação de crescimento das mesmas, e acabam usando antibióticos como promotor de crescimento ou como tratamento das doenças.

O uso dos antibióticos não é restrito aos tratamentos terapêuticos mas também são utilizados em doses subterapêuticas para atuarem como promotores de crescimento podendo melhorar os resultados de desempenho dos peixes e, acabam justificando seu emprego (BARROS et al., 2012). Essa aplicação contínua e excessiva geram grandes preocupações para a população mundial, já que estes animais são destinados ao consumo humano, e existe a possibilidade destas bactérias e seus genes de resistências serem transferidas para a 
microbiota humana reduzindo a eficiência dos antimicrobianos (BEZERRA et al., 2017) e desencadeie a chamada resistência bacteriana (GARCIA-MIGURA et al., 2014).

Poucos antibióticos são legalmente aprovados para uso na aquicultura e vários países rejeitam a importação de pescado tratado com antibióticos sintéticos (GASTALHO; SILVA; RAMOS, 2014). Para mitigar o emprego de antibiótico torna-se necessário buscar alternativas de substituição destes produtos, fazendo com que estas propriedades e o setor aquicola consigam garantir sustentabilidade à atividade, com retorno econômico e o desenvolvimento regional sem gerar a resistência antimicrobiana.

Dentre os fitoterápicos, os óleos essenciais têm apresentado destaque na aquicultura por fornecerem compostos seguros e ecológicos em substituição aos antibióticos e compostos químicos, bem como possuem ações benéficas no status imunológico e controle de doenças dos peixes (AWAD; AWAAD, 2017).

Os óleos essenciais são compostos aromáticos voláteis retirados das plantas pelo processo chamado de destilação, arraste por vapor (hidrodifusão) ou extração com uso de solventes (TONGNUANCHAN; BENJAKUL, 2014). Comumente derivam de compostos de terpenos hidrocarbonetos como álcoois, cetonas, aldeídos estéres e fenóis (SUTILI et al., 2017).

Os extratos herbais possuem um mecanismo de ação que promovem alterações benéficas na microbiota intestinal, resultando em efeito imunomodulatório que permite a redução do estresse imunológico. Além disso, podemos ter outros fatores que podem ocasionar estresse oxidativo nos tecidos dos animais tratados como podemos citar a própria poluição ambiental, o que acarreta na abertura de portas de entradas para patógenos. (PEREIRA et al., 2015).

Com isso objetivou-se avaliar nesse estudo o efeito dos extratos herbais como promotores de crescimento diante das características zootécnicas de desempenho de juvenis de tilápias, além de avaliar a contagem microbiana intestinal nos diferentes tratamentos.

\section{MATERIAL E MÉTODOS}

O presente estudo foi conduzido nas instalações do laboratório de aquicultura da UNOESC Xanxerê, campus I, sendo utilizadas 120 tilápias da linhagem GIFT, com aproximadamente três centímetros de comprimento. O período experimental de 42 dias ficou compreendido entre 04 de setembro de 2018 e 16 de outubro de 2018. As tilápias foram distribuídas no primeiro dia de alojamento em delineamento experimental inteiramente casualizado, sendo composto por três tratamentos, constituídos por quatro repetições, com 10 animais em cada repetição. $\mathrm{O}$ aditivo testado foi um composto de extratos herbais contendo óleo essencial à base de carvacrol (oriundo do orégano), eugenol (oriundo do cravo da índia) e timol (oriundo do tomilho), possuindo as proporções de $30 \%, 30 \%$ e $40 \%$, respectivamente. Os tratamentos, utilizando o blend de extratos herbais, foram os seguintes: $0 \mathrm{mg} / \mathrm{kg}$ de extratos herbais, $50 \mathrm{mg} / \mathrm{kg}$ de extratos herbais e $100 \mathrm{mg} / \mathrm{kg}$ de extratos herbais.

Os parâmetros químicos essenciais de qualidade d'água $(\mathrm{pH}$ e as concentrações de oxigênio dissolvido) seguiram valores recomendados para a espécie, entretanto a temperatura esteve um pouco abaixo do ideal em função da realização do experimento em um período de transição entre inverno e primavera. Em relação à densidade, observou-se baixa estocagem nas unidades experimentais, 
(caixas de 100 litros de água com sistema de recirculação e renovação de água).

A quantidade de ração ofertada foi de $3 \%$ em relação à biomassa em cada unidade experimental com o arraçoamento efetuado duas vezes ao dia. As pesagens foram realizadas nos dias 0,30 e 60 dias do experimento, para determinação do ganho de peso dos peixes.

Para a análise da microbiota intestinal, aos 60 dias de experimento foi selecionada, aleatoriamente, uma tilápia por grupo para eutanásia e colheita de lavado intestinal. Os peixes foram eutanasiados de acordo com as normas de bemestar animal recomendadas pelo CONCEA/MCTI (BRASIL, 2013), com protocolo CEUA 075/2017. Primeiramente o órgão foi dissecado de forma asséptica, e o lavado intestinal foi realizado através de "Flush" injetando-se no lúmen intestinal $10 \mathrm{ml}$ de solução salina $0,85 \%$, sendo este depositado em tubo de ensaio estéril, cujo lavado foi armazenado sob refrigeração e processado no mesmo dia da colheita.

Para a quantificação de mesófilos aeróbios aplicou-se a técnica de plaqueamento em superfície segundo Silva et al. (2010), utilizando o meio de cultura PCA (Plate Count Agar, Oxoid). Para tanto, Todas as amostras foram diluídas até $10^{-2}$ em solução salina a 0,85\%, estéril, e inoculadas no meio (inóculos de $0,1 \mathrm{~mL}$ de cada diluição por placa). Após a incubação $\left(37^{\circ} \mathrm{C} / 48 \mathrm{~h}\right)$ no meio PCA, foram contadas todas as colônias presentes $O$ número de unidades formadoras de colônia por mililitro (UFC $\mathrm{mL}^{-1}$ ) das amostras foi calculado multiplicando-se a o número de colônias contadas nas placas pelo inverso da diluição em que a contagem foi realizada.

As amostras também foram inoculadas em ágar sangue ovino 5\% e ágar Mac Conkey para identificação dos micro-organismos mais prevalentes. As placas foram incubadas a $37^{\circ} \mathrm{C}$ por 24 à $48 \mathrm{hs}$, sendo os micro-organismos identificados de acordo com as características morfo-tintoriais apresentadas segundo descrição de Markey et al. (2013). Os dados de desempenho e de avaliação contagem microbiana intestinal foram submetidos a análise de variância e as medias submetidas ao teste SNK a 0,05 de significância, através do software SAS (2011).

\section{RESULTADOS E DISCUSSÃO}

Os dados de desempenho estão apresentados na Tabela 1, nos quais não foram constatadas alterações $(P>0,05)$ em todas as variáveis avaliadas.

TABELA 1. Desempenho de tilápias alimentadas com diferentes níveis de extratos herbais

\begin{tabular}{ccccc}
\hline $\begin{array}{c}\text { Concentração } \\
\text { na Dieta }\end{array}$ & $\begin{array}{c}\text { Peso médio 15 } \\
\text { dias }(\mathrm{g})\end{array}$ & $\begin{array}{c}\text { Peso médio 30 } \\
\text { dias }(\mathrm{g})\end{array}$ & $\begin{array}{c}\text { Comprimento } \\
\text { médio }(\mathrm{mm})\end{array}$ & $\begin{array}{c}\text { Largura } \\
(\mathrm{cm})\end{array}$ \\
\hline $0 \mathrm{mg} / \mathrm{Kg}$ & 10.12 & 14.52 & 9.37 & 2.61 \\
$50 \mathrm{mg} / \mathrm{Kg}$ & 9.95 & 13.95 & 9.33 & 2.52 \\
$100 \mathrm{mg} / \mathrm{Kg}$ & 10.27 & 14.12 & 9.31 & 2.58 \\
\hline Valor P & 0.540 & 0.583 & 0.875 & 0.227 \\
CV $(\%)$ & 3.96 & 5.49 & 2.00 & 2.47 \\
\hline
\end{tabular}

Não houve diferença $(P>0,05)$ entre os peixes dos diferentes tratamentos para a variável ganho de peso. Tal achado está de acordo com Campagnolo et. al. (2013) que ao testarem diferentes doses ( 0 a $200 \mathrm{mg} / \mathrm{kg}$ ) de um aditivo comercial micro encapsulado, à base de óleo essencial de orégano, canela, alecrim e extrato de 
pimenta, também não encontraram evidências de efeito para ganho de peso, taxa de crescimento e conversão alimentar.

Em relação à contagem microbiana intestinal, as tilápias alimentadas com dietas contendo extratos herbais apresentaram menores valores de unidades formadoras de colônias/ml $(\mathrm{P}<0,05)$ quando comparadas aos peixes alimentados com a dieta controle (Tabela 2). Fato esse, que comprova a capacidade dos extratos herbais de atuarem como moduladores da microbiota intestinal. Immanuel et al. (2009), observaram que o efeito dos extratos herbais de mais de 50 plantas tais como: promotores de crescimento, imunoestimulantes, antibacterianos, antivirais, antifúngicos, anti-estresse, estimuladores do apetite e estimulantes da reprodução.

As cepas encontradas no cultivo foram comuns aos tratamentos com inclusão e o tratamento sem inclusão, sendo possível verificar que as diferentes dosagens aplicadas no estudo, não foram suficientes para eliminar totalmente as cepas de determinadas bactérias.

TABELA 2. Contagem de unidades formadoras de colônias (UFC) de conteúdo intestinal de tilápias alimentadas com diferentes níveis de extratos herbais.

\begin{tabular}{ccc}
$\begin{array}{c}\text { Níveis de } \\
\text { inclusão }\end{array}$ & UFC/ml & Bactérias Isoladas \\
\hline ppm & $24,6 \times 10^{4}$ & $\begin{array}{c}\text { Alcalígenes faecalis; Escherichia } \\
\text { coli; }\end{array}$ \\
50 ppm & $8,86 \times 10^{4}$ & $\begin{array}{c}\text { Acinetobacter sp.; Escherichia } \\
\text { coli; }\end{array}$ \\
$100 \mathrm{ppm}$ & $8,61 \times 10^{4}$ & $\begin{array}{c}\text { Alcalígenes faecalis; Escherichia } \\
\text { coli; } \text { Acinetobacter sp.. }\end{array}$ \\
\hline
\end{tabular}

Segundo Nayak (2010), a microbiota dos peixes é caracterizada por uma enorme variedade de microrganismos aeróbios, anaeróbios, benéficos e oportunistas que interagem entre si, e a colonização microbiana, o estabelecimento, composição e diversidade no trato é um processo complexo e é reflexo da composição microbiana da água, do tipo de dieta fornecida aos peixes e do ambiente. $O$ efeito como modulador de flora intestinal pode ser uma característica relevante para o uso dos extratos herbais, pois, com isso, é possível eliminar ou coibir a ação de alguns patógenos do trato digestivo com a exclusão competitiva. Muitas doenças infecciosas são iniciadas através da colonização da mucosa intestinal pelas bactérias patogênicas e a eficiência da barreira intestinal contra essas bactérias depende da produção de muco, da integridade epitelial e da presença e balanço entre as bactérias comensais, as quais mantêm a homeostase intestinal e a saúde dos peixes (TORRECILLAS et al., 2012).

É possível que as dosagens utilizadas no presente estudo não foram suficientes para estimular ou reprimir o crescimento. Por outro lado, o uso de doses mais elevadas de óleos essenciais e extratos herbais na dieta tem sido frequentemente recomendado, seja para promover uma melhora na imunidade em alevinos de tilápias (YIN et al., 2006) e para melhorar o desempenho zootécnico.

Houve alto percentual de sobrevivência $(98,4 \%)$ dos alevinos durante 0 período experimental, podendo indicar que nos níveis testados, o aditivo não apresentou toxidez, proporcionando segurança na sua utilização. O uso de aditivos como promotores de crescimento pode promover um aumento das 
vilosidades, o que é associado à melhor eficiência, ao aproveitamento da ração e à uma excelente saúde intestinal. (CAMPAGNOLO et al., 2013). O animal que aproveita melhor o nutriente oferecido pela ração, consequentemente, terá um incremento positivo em seu status sanitário, além de melhorar o desempenho produtivo. Entretanto, o comportamento dos dados observados foi diferente dos dados relatados na literatura comparada, indicando a necessidade de maiores estudos neste campo do conhecimento.

\section{CONCLUSÕES}

A partir dos dados obtidos no presente estudo, é possível concluir que o uso de extratos herbais, nas dosagens testadas, não foi suficiente para alterar significativamente o desempenho zootécnico dos alevinos de tilápias. Entretanto, foi capaz de influenciar positivamente na flora intestinal, o que sugere que dosagens maiores devem ser testadas a fim de verificar a eficácia e a viabilidade dos extratos herbais como promotores de crescimento em peixes.

\section{REFERÊNCIAS}

AWAD E; AWAAD A. Role of medicinal plants on growth performance and immune status in fish. Fish \& Shellfish Immunology v.67, n.40-54, 2017. Disponível em: <https://doi.org/10.1016/j.fsi.2017.05.034>doi:10.1016/j.fsi.2017.05.034

BARROS, R.; VIEIRA, S.L.; FAVERO, A.; TASCHETTO, D.; MASCARELLO, N. C.; CEMIN, H. S. Reassessing flavophospholipol effects on broiler performance. Revista Brasileira de Zootecnia, v. 41, n. 12, p. 2458-2462, 2012. Disponivel em: < http://dx.doi.org/10.1590/S1516-35982012001200011

BARROSO, R.M.; PINCINATO, R.B.M.; MUNOZ, A.E.P. O mercado da tilápia: $2^{\circ}$ trimestre de 2017 e análise da estrutura do preço da tilápia no varejo. Embrapa Informativo Mercado da Tilápia n. 11. 2017. Disponível em: <https://ainfo.cnptia.embrapa.br/digital/item/162159/1/cnpasa-2017-mt11.pdf>

BEZERRA, W. G. A.; ; HORN, R.H. ; SILVA, I.N.G ; TEIXEIRA, R.S.C. ; LOPES, E.S. ; ALBUQUERQUE, Á.H. E CARDOSO, W. C. Antibióticos no setor avícola: uma revisão sobre a resistência microbiana. Arquivos de Zootecnia, v. 66, n. 254, p. 301-307, 2017. Disponivel em: <https://doi.org/10.21071/az.v66i254.2335> doi:10.21071/az.v66i254.2335

BRASIL. Ministério da Ciência, Tecnologia e Inovação. Diretrizes para a prática de eutanásia do CONCEA. Brasília: MCTI, 2013

CAMPAGNOLO, R.; FRECCIA, A.; BERGMANN, R. R.; MEURER, F.; BOMBARDELLI, R. A. Óleos essenciais na alimentação de alevinos de tilápia do Nilo. Revista Brasileira de Saúde e Produção Animal, v.14, n.3, p.565-573, 2013. https://dx.doi.org/10.1590/S1519-99402013000300020

GARCIA-MIGURA, L.; HENDRIKSEN, R. S.; FRAILE, L.; AARESTRUP, F. M. Antimicrobial resistance of zoonotic and commensal bacteria in Europe: The missing link between consumption and resistance in veterinary medicine. Veterinary Microbiology, v.170, n. 1, p.1-9, 2014. Disponível em: 
<http://dx.doi.org/10.1016/j.vetmic.2014.01.013> doi:10.1016/j.vetmic.2014.01.013

GASTALHO, S.; SILVA, G.J.D.; RAMOS, F. Antibiotics in aquaculture and bacterial resistance: Health care impact. Acta Farmacêutica Portuguesa, v.3, p.28-44, 2014. doi: 10.1590/S1516-35982012001200011

HU, Z.; LEE, J.W.; CHANDRAN, K.; KIM, S.; BROTTO, A.C.; KHANAL, S.K. Effect of plant species on nitrogen recovery in aquaponics. Bioresource technology. n. 188, p. 92-98, 2015.

IMMANUEL, G.; UMA, R. P.; IYAPPARAJ, P.; CITARASU, T.; PETER, S. M. P.; BABU, M. M.; PALAVESAM, A. Extratos vegetais de plantas medicinais melhoram o crescimento, a atividade imunológica e a sobrevivência da tilápia Oreochromis mossambicus. Journal Fish Biology, v. 74, p. 1462-1475, 2009. Disponível em: <https://doi.org/10.1111/j.1095-8649.2009.02212.x> doi:10.1111/j.10958649.2009.02212.x

KALAMA, B.S.; MEDALE, F.; PANSERAT, S. Utilization of dietary carbohydrates in farmed fishes: New insights on influencing factors, biological limitations and future strategies. Aquaculture, v.467, p.3-27, 2017. Disponível em:

<https://doi.org/10.1016/j.aquaculture.2016.02.007>doi:10.1016/j.aquaculture.2016.0 2.007

MARKEY, B.K.; LEONARD, F.C..; ARCHAMBAULT, M.; CULLINANE, A.; MAGUIRE, D. Clinical Veterinary Microbiology. London: MOSBY Elsevier, 2013. 901p. Disponível em: <doi: 10.5433/1679-0359.2016v37n3p1369> doi: 10.5433/16790359.2016v37 n3p1369

NAYAK, S. K. Role of gastrointestinal microbiota in fish. Aquaculture Research, v. 41, n.11, 1553-1573, 2010. Disponível em:< https://doi.org/10.1111/j.13652109.2010.02546.x >doi:10.1111/j.1365-2109.2010.02546.x

PEREIRA, M.A.; MACHIORI, N.C.; JERONIMO, G.T.; MOURIÑO, J.L.P.; MARTINS, M.L. Sanidade e Perspectivas para ranicultura ( $1^{\circ}$ volume). 2015. In.: Tavares-Dias, M.; MARIANO, W.S. Aquicultura no Brasil: novas perspectivas. São Carlos: Pedro \& João Editore, 2015.

SEBRAE - Serviço Brasileiro de Apoio as micro e pequenas Empresas. Aquicultura no Brasil: série de estudos mercadológicos. Brasília, 2015. Disponível em: <http://www.bibliotecas.sebrae.com.br/chronus/ARQUIVOS_CHRONUS/bds/bds.nsf/ 4b14e85d5844cc99cb32040a4980779f/\$File/5403.pdf>

SUTILI, F.J.; GATLIN, D.M.; HEINZMANN, B.M.; BALDISSEROTTO, B. Plant essential oils as fish diet additives: benefits on fish health and stability in feed. Reviews in Aquaculture, v.10, n.3, p.716-726, 2017. Disponível em: < https://doi.org/10.1111/raq.12197> doi: 10.1111/raq.12197

TELLI, G.S.; RANZANI-PAIVA, M.J.T.; DE CARLA DIAS, D.; SUSSEL, F.R.; ISHIKAWA, C.M.; TACHIBANA, L. Dietary administration of 
Bacillus subtilis on hematology and non-specific immunity of Nile tilapia Oreochromis niloticus raised at different stocking densities. Fish \& shellfish immunology, v.39, p.305-311, 2014.

Disponível em: < https://doi.org/10.1016/j.fsi.2014.05.025> doi: 10.1016/.jfsi.2014.05.025

TONGNUANCHAN, P.; BENJAKUL, S. Essential oils: extraction, bioactivities, and their uses for food preservation. Journal of food science, v.79, n.7, p.1231-R1249, 2014. 29 Disponível em: <https://doi.org/10.1111/1750-3841.12492> doi:10.1111/1750-3841.12=492

TORRECILLAS, S.; MAKOL, A.; CABALLERO, M. J.; MONTERO, D.; DHANASIRI, A. K.; SWEETMAN, J.; IZQUIERDO, M. Effects on mortality and stress response in European sea bass, Dicentrarchus labrax (L.), fed mannan oligosaccharides (MOS) after Vibrio anguillarum exposure. Journal of Fish Diseases, v.35, n.8, p.591-602, 2012. Disponível em: <https://doi.org/10.1111/j.1365-2761.2012.01384.x> doi:10.1111/j.1365-2761.2012.01384.x

YIN, G.; JENEY, G.; RACZ, T.; XU, P.; JUN, X.; JENEY, Z. Effect of two Chinese herbs (Astragalus radix and Scutellaria radix) on non-specific immune response of tilapia, Oreochromis niloticus. Aquaculture, v.253, n.1-4, p.39-47, 2006. Disponivel em:< https://doi.org/10.1016/j.aquaculture.2005.06.038> doi:10.1016/j.aquaculture.2005.06.038 